\title{
Dimorphic Goat Amelogenin Alleles on Sex Chromosomes for Gender Determination of Preimplantation Embryos
}

\author{
Hsiao-Ling Chen, Tung-Chou Tsai, Jan-Chi Huang, De-Chi Wang, and Chuan-Mu Chen
}

\begin{abstract}
Amelogenin (AMEL) is a conserved gene located on the sex chromosomes of mammals. It is involved in the formation of enamel, which is the hard, white material that forms the protective outer layer of each tooth. In this study, we first cloned the coding sequences of the goat $A M E L X$ and $A M E L Y$ transcripts from female and male lamb enamel tissues during tooth development. All 207 amino acids of the putative AMEL proteins from the cDNA coding regions of both sex chromosomes were the same, but the $A M E L$ sequences of the 3'-untranslated regions (UTR) were different. The results showed that the nucleotide sequences of intron 5 of the goat $A M E L X$ and $A M E L Y$ genes contained multiple deletions/insertions and had only $48.5 \%$ identity. Based on the dimorphic $A M E L$ intron sequences, a set of sex-specific primers was successfully applied to goat gender determination. A high sensitivity for sex determination was reached with a minimal amount of template, such as a trace amount of genomic DNA from a single blastomere isolated from embryos at the blastula stage among different strains of goats.
\end{abstract}

Index Terms-Goat amelogenin gene, polymorphic DNA, embryo sexing, single blastomeres, preimplantation.

\section{INTRODUCTION}

Goats are important livestock for multiple purposes, such as high-quality meat, wool, and milk sources and for the production of valuable recombinant proteins in transgenic goat milk for agriculture, veterinary medicine or pharmaceutical uses [1]-[4]. Recent studies have demonstrated that goat offspring can be easily produced from in vivo- and in vitro-fertilized eggs by embryo transfer, either fresh or frozen/thawed [5]. In addition, it is desirable to control the sex ratios in the goat industry.

Amelogenin (AMEL) is the major protein found in developing tooth enamel and belongs to a family of extracellular matrix (ECM) proteins. AMEL is involved in the formation of enamel, which is the hard, white material

Manuscript received May 2, 2013; revised July 13, 2013. This work was supported in part by the grant NSC-100-2313-B-005-012 from the National Science Council and the Ministry of Education, Taiwan, Republic of China, under the ATU plan.

Chuan-Mu Chen and T. C. Tsai are the Department of Life Sciences, National Chung Hsing University, 250, Kuo-Kuang Road, Taichung 402 , Taiwan (e-mail: chchen1@dragon.nchu.edu.tw, proteinase86@ yahoo.com.tw).

H. L. Chen is with the Department of Bioresources, Da-Yeh University, Changhwa 515, Taiwan (e-mail: bellchen@mail.dyu.edu.tw).

J. C. Huang, D. C. Wang, and Hengchun Branch are the Livestock Research Institute, Council of Agriculture, Taiwan (e-mail: jchuang@mail.tlri.gov.tw; dcwang@mail.tlri.gov.tw). that forms the protective outer layer of each tooth [6]. One copy of the amelogenin gene is located on each of the sex chromosomes ( $\mathrm{X}$ and $\mathrm{Y}$ ). The AMELX gene, which is located on the X chromosome (Xp22.31- p22.1), makes almost all of the amelogenin. The copy of the amelogenin gene on the $\mathrm{Y}$ chromosome (Yp11.2), AMELY, makes very little amelogenin and is not required for enamel formation [7].

A number of approaches have been used to identify the gender of preimplantation mammalian embryos including cytological analysis of Barr bodies or sex chromosomes [8], detection of the male-specific $\mathrm{H}-\mathrm{Y}$ antigen [9], quantitative comparison of $\mathrm{X}$-linked enzyme activity between male and female embryos [10], hybridization with a male-specific probe [11], and determination of the differences in the developmental rates between male and female embryos [12]. These procedures are generally time-consuming or inaccurate. However, some of these problems have been improved by the use of polymerase chain reaction (PCR) [13], [14], such as amplification of the SRY gene, which is associated with the testis-determining factor [15], or relevant Y- specific repetitive sequences [16], [17].

In the present investigation, we first cloned and sequenced the goat $A M E L$ gene cDNAs from the Alpine strain of dairy goat. The sex-specific polymorphic fragments in the goat $A M E L X$ and AMELY genes were then identified in each intron sequence. Furthermore, we extended the use of the $\mathrm{X} / \mathrm{Y}$ homologous $A M E L$ analysis to determine the genders of goat embryos by single- blastomere PCR amplification. The sensitivity and fidelity of the newly created PCR sexing technique also tested in different strains of dairy goat.

\section{MATERIAls AND MethodS}

\section{A. cDNA Cloning of Goat Amelogenin Genes}

Total RNAs were isolated from $1.0 \mathrm{~g}$ of goat ameloblast tissues with TRIzol $^{\mathrm{TM}}$ reagent and according to the manufacturer's protocol (Invitrogen, San Diego, CA). $300 \mu \mathrm{g}$ of total RNA were used to isolate the poly $\left(\mathrm{A}^{+}\right) \mathrm{mRNA}$ using the FastTrack ${ }^{\circledR}$ MAG mRNA isolation kit (Invitrogen). An aliquot of $5 \mu \mathrm{l}$ poly $\left(\mathrm{A}^{+}\right) \mathrm{mRNA}$ was used for first-strand cDNA synthesis by SuperScript ${ }^{\mathrm{TM}}$ III reverse transcriptase (Gibco/BRL, Burlington, ON) as described [18]. A mature goat amelogenin cDNA fragment $(0.7 \mathrm{~kb})$ was amplified by PCR using a pair of primers, pAMEL-F (5'CACTGAGAACGTGTGTTCAA AG-3') and pPolyT-R (5'-TTTTTTTTTTTTTTTTTTTGTA-3'). The PCR product 
was cloned into pGEM T-Easy Vector Systems (Promega, Madison, WI) and the sequence was verified by nucleotide sequencing [19].

\section{B. Isolation of Gender-Specific Amelogenin Gene Fragments}

To identify the gender-specific sequence, the intron 5- X and intron 5-Y of goat AMEL genes were amplified by PCR. The upstream primer oligonucleotide was 5'AGCAACAGACAAGACCAAG-3' which located on fifth exon sequence homologous to both goat AMEL-X and AMEL-Y genes. And the downstream primers were 5'-TTTACTTCAGGTCTCTTCTC-3' and 5'-GTAGAA TGATTATGGGCACAAA-3' which located on sixth exon and 3'-untranslation region homologous to goat AMEL-X and AMEL-Y genes, respectively. PCR products were generated a 1,577-bp and a 1,780-bp fragment in the female and male, respectively. These amplicons were then cloned into pCR 2.01 vector using the TOPO cloning kit (Invitrogen, San Diego). The intron 5 equences of goat AMEL-X and AMEL-Y clones were determined using the BigDye terminator cycle sequencing system (Applied Biosystems Inc., Foster, CA), as described previously [20], [21]. The difference between intron 5-X and intron 5-Y of AMEL genes was analyzed under comprehensively comparison of nucleotide sequences through the DNASTAR nucleic acid analysis computer software (Dnastar Inc., Madison, WI, USA). The similarity alignments of AMEL amino acids sequences among different species were performed using the GCG Sequence Analysis Software (Genetic Computer Group, WI) [22].

\section{Micromanipulation of Goat Embryos}

Goat embryos were collected by means of surgical method, flush the oviducts at the fifth to sixth day after insemination and obtain unimplanted embryos at morula or blastula stage [23]. In order to obtain higher embryo numbers, every donor goat had been treated with endocrine so as to achieve the object of superovulation. Such a superovulation treatment comprised of administrating intramuscular of follicular stimulating hormone (FSH) to the donor goat sequentially for 4 days since eighth day of estrous cycle twice a day with 12 $\mathrm{h}$ interval and the dosage was decreased daily as 4-, 3-, 2- and 1-mg, respectively. As the first dosage at the third day, co-administrated with 1000 I.U. human chorionic gonadotropin (HCG) which resulted in detection of estrous after 54 hours whereupon gave two artificial inseminations (AI) with $12 \mathrm{~h}$ interval. The goat embryos were collected with a sterile glass capillary tube via surgical method. The collected embryo was transferred into another petri dish where it was rinsed more than ten times. Thereafter, it was placed under a phase contrast microscope at $400 \mathrm{X}$ amplification for sampling of single blastomere at morula or blastula stage. The single blastomere obtained was placed directly in a $0.5-\mathrm{mL}$ thin wall microcentrifuge tube and frozen quickly in a refrigerator at $-70^{\circ} \mathrm{C}$ until PCR sexing. As soon as the single blastomere had been sampled, the goat embryo was placed into a DPBS culture medium (Gibico-BRL, Gaithersburg, MD) containing 10\% serum and cultured in an incubator at $39^{\circ} \mathrm{C}$ to cure the mechanical damage at its zone pellucida [24].

\section{Single-Blastomere PCR Gender Determination}

For goat embryos sexing, we developed a triple- primer set of PCR amplification system, the upstream primer (gAMEL-XY-U1: 5'-AGCAACAGACAAGACC AAGC-3') matches completely the intron 5-X and intron 5-Y of AMEL gene sequences, while the two allele- specific downstream primers (gAMEL-Y-S1: 5'-TGCCA TATAGATAGACAAGC-3' and gAMEL-X-S2: 5'-ACC CACCATAAAAGCTATTG-3'), allows unambiguous identification of both $\mathrm{Y}$ and $\mathrm{X}$ chromosome signals in a single reaction, respectively. The PCR products derived from a female embryo (XX) has a length of 246-bp, while those products derived from a male embryo (XY) have lengths of 246-bp and 206-bp, thereby determining the sex type of the goat embryo. The biopsy sample was spin down for a few seconds and denatured by heating the tube on a PCR apparatus (MJ Research Inc., Waltham, MA) at $97^{\circ} \mathrm{C}$ for $5 \mathrm{~min}$ then chilling on ice. A reaction mixture consisting of $20 \mathrm{mM}$ Tris- $\mathrm{HCl}(\mathrm{pH} 8.8), 10 \mathrm{mM}\left(\mathrm{NH}_{4}\right)_{2} \mathrm{SO}_{4}, 10 \mathrm{mM}$ $\mathrm{MgSO}_{4}, 0.1 \%$ Triton-X 100, $0.1 \mathrm{mg} / \mathrm{ml} \mathrm{BSA}, 0.4 \mu \mathrm{M}$ of each primer, $0.2 \mathrm{mM}$ of $\mathrm{dNTP}$ and 2.5 units of Taq polymerase (Perkin-Elmer Cetus, Foster) was added to each sample in a $0.5 \mathrm{ml}$ tube (final volume, $50 \mu \mathrm{l}$ ). A total of 50 cycles of polymerization was carried out by two-stage procedure. The first stage was aimed at increasing the binding efficiency of the primers on the single-cell template, the time of incubation for denaturation, annealing and extension were set at 10, 10 and $15 \mathrm{sec}$ at 94,54 and $72^{\circ} \mathrm{C}$, respectively. The following 30 cycles was focused on the amplification of gene fragment and the specificity of PCR products by means of increasing the annealing temperature to $55^{\circ} \mathrm{C}$. The final extension time was increased to $1 \mathrm{~min}$ at $70^{\circ} \mathrm{C}$ and then cooling down to room temperature (Chen et al., 1999). PCR products were analyzed on $2 \%$ high- resolution Syner gel (Diversified Biotech, Boston, MA) containing ethidium bromide.

\section{E. Statistical Analysis}

All of the data were performed by using the student t- test statistical analysis. A difference between two means was considered statistically significant based on $* P<0.05$.

\section{RESLTS AND DISCUSSION}

\section{A. Molecular Cloning of Amelogenin mRNA Transcripts from Male and Female Goats}

The full-length 624-bp goat amelogenin ( $g A M E L$ ) mRNAs each encoded an identical 16-aa secretory signal peptide followed by a 191-aa mature polypeptide, as shown in Fig. 1. In this study, RT-PCR was applied to identify and clone the goat $A M E L$ cDNA fragments from enamel tissue of both male and female lambs during tooth development. A major 752-bp gAMEL cDNA product was amplified from the AMELX gene (GenBank accession number: AF215889) and was present in male and female samples, whereas a minor 746-bp $g A M E L$ cDNA product were amplified from the AMELY gene (GenBank accession number: AF215890) and was only present in male samples. The sequences of the 5'-UTR and exons were identical between the goat AMELX and AMELY mRNA transcripts, but high nucleotide diversity 
was found in their 3'-UTRs (Fig. 1).

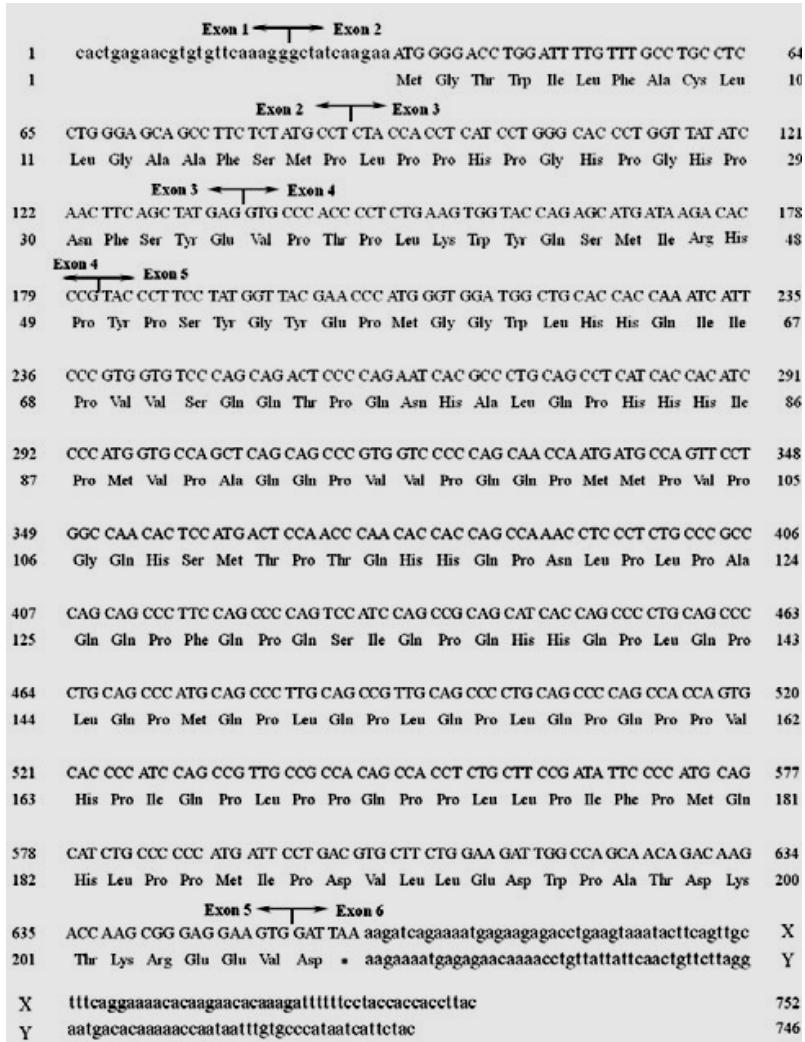

Fig. 1. The complete coding sequence of the goat AMELX and AMELY genes cloned from developing ameloblast tissues of female and male alpine dairy goats. The numbering of the amelogenin cDNA and translated protein sequences begins at the translational start codon. The number of the first nucleotide in each row is provided at the left. "T" bars with arrows indicate exon junctions and the exon numbers that border the sites. An asterisk (*) marks the translational stop codon. The different sequences of the 3'-UTRs present in AMELX and AMELY are marked with X and Y, respectively.

\section{B. Structure Analysis of Amelogenin Protein among Different Species}

The putative 207-amino acid sequence of the goat AMEL protein from the coding sequence was deposited in NCBI database (GenBank accession number: AAG43997). The alignment of the goat AMEL peptide sequence with sequences from different species, including bovine, pig, human, and mouse, was constructed using the GCG Sequence Analysis System. The 16-aa secretory signal peptide and biomineral matrix domain located in the $\mathrm{N}$-terminus of the goat AMEL mature protein are highly conserved among different mammalian species (Fig. 2). More diversity was found in the C-terminus of the AMEL protein in this study. It has also been reported that an alignment of the variable region of the exon 6-derived amino acid sequence of 17 other species shows more deletions and variations (Sire et al., 2005). The secondary structure of AMEL has been a challenging problem for structural biology because it has a rigid structure that arises from contiguous $\beta$-turns, which impart a $\beta$-spiral structure (Renugopalakrishnan, 2002). In this study, we found that goat AMEL contains a 24-residue tandem repeat sequence of $\beta$-spiral structure QHH-QPL-QPL-QPM-QPL-QPL-QPL-QPQ (Fig. 2). This $\beta$-spiral turns may offer an ideal structure for the passage of calcium ions through amelogenin.

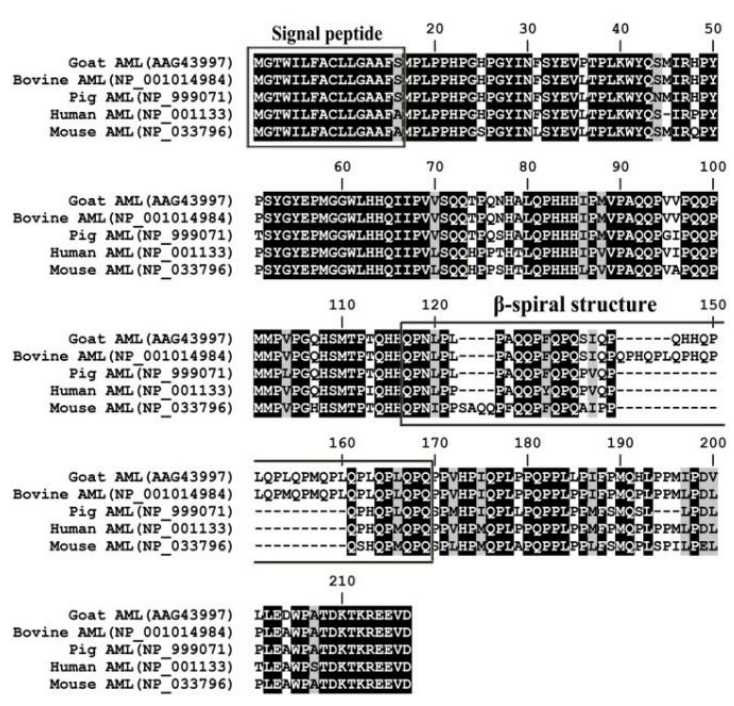

Fig. 2. Alignment of the goat, bovine, pig, human and mouse amelogenin amino acid sequences deduced from genomic DNA (Human) or CDNA (goat, bovine, pig and mouse). Amino acids are represented by the one-letter code. Identical sequences are marked with a black background, and similar sequences are marked with a gray background. The dashes represent gaps in the amino acid sequence. The signal secretion peptide is encoded by amino acids $1-16$, as shown in the $\mathrm{N}$ - terminus. A special $\beta$-spiral structure present in the highly variable region of AMEL is marked with an open box.

\section{Identification of Sex-Specific Sequences between AMEL-X and AMEL-Y Genes}

To identify the gender-specific sequences, the sequences of intron 5 of the goat $A M E L$ alleles on the $\mathrm{X}$ and $\mathrm{Y}$ chromosomes were amplified by PCR. The PCR products generated were 1,577-bp and 1,780-bp in females and males, respectively. The similarity between the newly cloned intact intron 5 sequences of goat $A M E L X$ and $A M E L Y$ was only $48.5 \%$. These results are consistent with the previous report that the sequence similarity of intron 5 is less than $30 \%$ between different species, whereas high degrees of similarity $(>80 \%)$ in the coding region are found among humans, swine, and bovine [25].

\section{A Multiplex PCR Sexing Using Amelogenin Gene Polymorphisms}

For PCR-based goat embryo sexing, a set of three primers was developed that spanned a 58-bp multiple deletion region in AMELY. The upstream primer (gAMEL-XY-U1) matched the exon 5 sequence that is identical between both goat $A M E L X$ and AMELY. The two downstream primers (gAMEL-Y-S1 and gAMEL-X- S2, as shown in Materials and Methods) matched sequences in intron 5-Y and intron 5-X that are identical between goat AMELX and AMELY, respectively. The three primers enabled the unambiguous identification of both $\mathrm{Y}$ and $\mathrm{X}$ chromosome signals in a single reaction. The PCR product derived from a female embryo (XX) had a length of 264-bp, while the products derived from a male embryo (XY) had lengths of 264-bp and 206-bp. Therefore, the number of bands generated indicated the sex of the goat embryo.

\section{E. A Multiplex PCR Sexing Using Amelogenin Gene Polymorphisms and Comparison with Chromosomal Karyotyping}

The sensitivity of the AMEL-based sexing assay was 
evaluated on a dilution panel of genomic DNA from male and female goats to simulate the DNA quantities that could be isolated from embryo biopsies. The AMELX and AMELY PCR products were detected with at least $5 \mathrm{pg}$ of genomic DNA, suggesting that this assay is suitable for sex diagnosis with as little as single cell. The PCR protocol and the three primers were successfully applied to sex determination in single blastomeres taken from 6- day-old embryos (Fig. 3 (A) ). Sample Nos. 3 and 4 showed a single 264-bp fragment and were interpreted as female. Sample Nos. 1 and 2 showed both the 264- and 206-bp amplification products and were interpreted as male (Fig. 3 (C) ). The results were fully confirmed by chromosomal karyotyping (Fig. 3 (B) ) and live births. Although the primer sequences were based on the cloned AMEL gene of Alpine dairy goats, they worked equally well with embryonic blastocysts isolated from the Saanen, Nubian, and Taiwan goat strains (data not shown). Therefore, this system may be useful for various popular dairy goats.

(A)

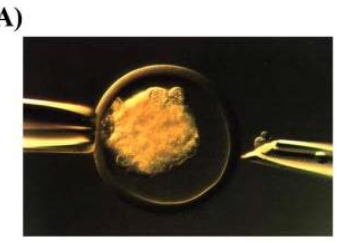

(B)

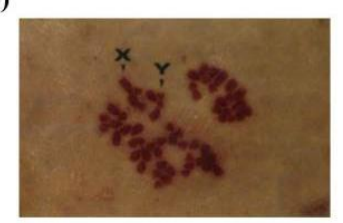

(C)

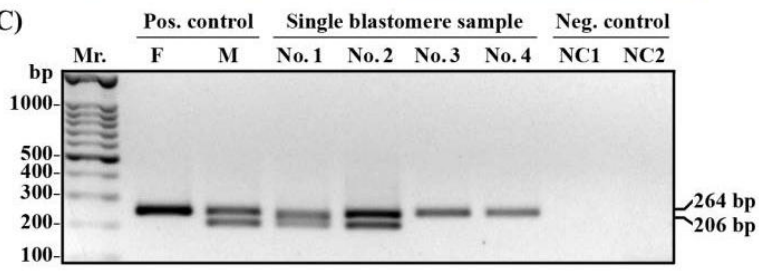

Fig. 3. PCR-based sexing by triplex primers of the goat $A M E L$ gene in single blastomeres. (A) Image represented the goat single blastomere biopsy. (B) Chromosomal karyotyping of goat blastomere to confirm the sexing results. (C) PCR products from a single biopsied goat blastomere in an embryo-sexing experiment. The gender-neutral $(264 \mathrm{bp})$ and the male-specific PCR products (206 bp) are indicated. Mr.: molecular size marker. A PCR reaction without an embryo blastomere was used as a negative control (NC). The amplified products were applied individually to the wells of a $2.0 \%$ high-resolution Synergel.

\section{CONCLUSION}

The performance trait of milk production is the most important genetic variable in the dairy industry. There is increasing demand in the marketplace for determination of the sex of an unborn bovine or goat fetus [24]. Owners want to know whether male and female goat contracts have been filled or they need to continue producing embryos from donor goats. The sex of the fetus can change the value of the pregnancy. Another economic benefit of embryo sexing is that it gives owners the ability to control the genetic background [26]. In addition to improved genetic control, gender preselection provides additional advantages for management and facility usage.

The $A M E L$ gene-based tests can be used for sex diagnosis of small amounts of genomic DNA obtained from different sources, including blood DNA and embryo biopsies. It also can be extensively used in several other applications including forensics, archaeozoology, and meat production and processing. Moreover, the sequences obtained of the
AMELX and AMELY alleles showed unanticipated highly polymorphisms, especially in the $\beta$ - spiral structure, which would be interesting to study further from an evolutionary perspective.

\section{ACKNOWLEDGMENT}

The authors would like to thank Dr. Jeffrey Conrad for critically reading the manuscript. This research was supported in part by grant NSC-100-2313-B-005-012 from the National Science Council and the Ministry of Education, Taiwan, Republic of China, under the ATU plan.

\section{REFERENCES}

[1] H. L. Chen, L. C. Wang, C. H. Chang, C. C. Yen, W. T. K. Cheng, S. C. Wu, C. M. Hung, M. F. Kuo, and C. M. Chen, "Recombinant porcine lactoferrin expressed in the milk of transgenic mice protects neonatal mice from a lethal challenge with enterovirus type 71," Vaccine, vol. 26, pp. 891-898, Feb. 2008.

[2] Y. T. Tung, H. L. Chen, C. C. Yen, P. Y. Lee, H. C. Tsai, M. F. Lin, and C. M. Chen, "Bovine lactoferrin inhibits lung cancer growth through suppression of both inflammation and expression of vascular endothelial growth factor," J. Dairy Sci., vol. 94, pp. 2095-2106, Apr. 2013.

[3] K. A. Jackson, J. M. Berg, J. D. Murray, and E. A. Maga, "Evaluating the fitness of human lysozyme transgenic dairy goats: growth and reproductive traits," Transgenic Res., vol. 19, pp. 977-986, Dec. 2010.

[4] D. J. Wells, "Genetically modified animals and pharmacological research," Handb. Exp. Pharmacol., vol. 199, pp. 213-26, 2010.

[5] D. Malader, S. K. Das, M. Mukesh, M. Sodhi, and S. L. Goswarmi, "Production of kids from in vitro fertilized goat embryos and their parentage assessment using microsatellite markers," Asian-Austral. J. Anim. Sci., vol. 20, pp. 842-907, 2007.

[6] C. Sedwick, "Amelogenin: a protein to smile about," PLoS Biol., vol. 7 , pp. e1000263, Dec. 2009.

[7] Y. Nakahori, O. Takenaka, and Y. Nakagome, "A human X-Y homologous region encodes amelogenin," Genomics, vol. 9, pp. 264-269, Feb. 1991.

[8] C. K. Hamilton, A. Combe, J. Caudle, F. A. Ashkar, A. D. Macaulay, P. Blondin, and W. A. King, "A novel approach to sexing bovine blastocysts using male-specific gene expression," Theriogenology, vol. 77, pp. 1587-1596, May 2012.

[9] J. C. Gardon, S. Aguera, and F. Castejon, "Sexing in vitro produced bovine embryos, at different stages of development, using rat H-Yantiserum," Theriogenology, vol. 62, pp. 35-43, Jul. 2004.

[10] M. Monk and A. H. Handyside, "Sexing of preimplantation mouse embryos by measurement of X- linked gene dosage in a single blastomere," J. Reprod. Fertil., vol. 82, pp. 365-368, Jan. 1988.

[11] J. Kobayashi, A. Sekimoto, H. Uchida, T. Wada, K. Sasaki, H. Sasada, M. Umezu, and E. Sato, "Rapid detection of male-specific DNA sequence in bovine embryos using fluorescence in situ hybridization," Mol. Reprod. Dev., vol. 51, pp. 390-394, Dec. 1998.

[12] K. P. Xu, B. R. Yadav, W. A. King, and K. J. Betteridge, "Sex-related differences in developmental rates of bovine embryos produced and cultured in vitro," Mol. Reprod. Dev., vol. 31, pp. 249-252, Apr. 1992

[13] K. M. Sullivan, A. Manncci, C. P. Kimpton, and P. Gill, "A rapid and quantitative DNA sex test: fluorescence- based PCR analysis of X-Y homologous gene amelogenin," Biotechniques, vol. 15, pp. 636-638, Oct. 1993.

[14] E. Pailhoux, P. Cribiu, S. Chaffaux, R. Darre, M. Fellous, and C. Cotinot, "Molecular analysis of 60, XX pseudohermaphrodite polled goats for the presence of SRY and ZFY genes," J. Reprod. Fertil., vol. 100, pp. 491-496, Mar. 1994

[15] A. H. Sinclair, P. Berta, M. S. Palmer, J. R. Hawkins, B. L. Griffiths, M. J. Smith, J. W. Foster, and P. N. Goodfellow, "A gene from the human sex- determining region encodes a protein with homology to a conserved DNA-binding motif," Nature, vol. 346, pp. 240-244, Jul. 1990.

[16] Y. Nakahori, K. Mitani, M. Yamada, and Y. Nakagome, "A human Y-chromosome specific repeated DNA family (DYZI) consists of a tandem assay of penta-nucleotides," Nucl. Acids Res., vol. 14, pp. 7569-7580, Oct. 1986

[17] A. Schroder, J. R. Miller, P. D. Thomsen, K. Roschlau, B. Avery, P. H. Poulsen, M. Schmidt, and M. Schwerin, "Sex determination of bovine 
embryos using the polymerase chain reaction," Anim. Biotechnol., vol. 1, pp. 121-133, 1990.

[18] H. L. Chen, J. Y. Huang, T. W. Chu, T. C. Tsai, C. M. Hung, C. C. Lin, F. C. Liu, L. C. Wang, Y. J. Chen, M. F. Lin, and C. M. Chen, "Expression of VP1 protein in the milk of transgenic mice: As a potential oral vaccine against for enterovirus 71 strain infection," Vaccine, vol. 26, pp. 2882-2889, Jun. 2008.

[19] Y. T. Tung, H. L. Chen, C. Y. Lee, Y. C. Chou, P. Y. Lee, H. C. Tsai, Y. L. Lin, and C. M. Chen, "Active component of Danshen (Salvia miltiorrhiza Bunge), tanshinone I, attenuates lung tumorigenesis via inhibitions of VEGF, Cyclin A, and Cyclin B expressions," Evid. Based Complement. Alternat. Med., vol. 2013, pp. e319247, Apr. 2013.

[20] C. J. Shen, W. T. K. Cheng, S. C. Wu, H. L. Chen, T. C.Tsai, S. H. Yang, and C. M. Chen, "Differential differences in methylation status of putative imprinted genes among cloned swine genomes," PLoS One vol. 7, pp. e32812, Feb. 2012.

[21] T. C. Tsai, W. Lin, S. H. Yang, W. T. Cheng, E. H. Cheng, M. S. Lee, K. Y. Chong, and C. M. Chen, "Granzyme G is expressed in the two-cell stage mouse embryo and is required for the maternal-zygotic transition," BMC Dev. Biol., vol. 10, pp. e88, Aug. 2010.

[22] F. C. Liu, H. L. Chen, W. Lin, Y. T. Tung, C. W. Lai, A. L.Hsu, and C. M. Chen, "Application of porcine lipase secreted by pichia pastoris to improve fat digestion and growth performance of postweaning piglets," J. Agric. Food Chem., vol. 58, pp. 3322-3329, Mar. 2010.

[23] T. C. Tsai, S. H. Wu, H. L. Chen, Y. T. Tung, W. T. Cheng, J. C. Huang, and C. M. Chen, "Identification of sex-specifc polymorphic sequences in the goat amelogenin gene for embryo sexing, "J. Anim. Sci., vol. 89, pp. 2407-2414, Aug. 2011

[24] C. M. Chen, C. L. Hu, C. H. Wang, C. M. Hung, H. K. Wu, K. B. Choo, and W. T. K. Cheng, "Gender determination in single bovine blastomeres by polymerase chain reaction amplification of sex-specific polymorphic fragments in the amelogenin gene," Mol. Reprod. Dev., vol. 54, pp. 209-214, Nov. 1999.

[25] C. C. Hu, C. Zhang, Q. Qian, O. H. Ryu, J. Moradian- Oldak, A. G. Fincham, and J. P. Simmer, "Cloning, DNA sequence, and alternative splicing of opossum amelogenin mRNAs," J. Dental Res., vol. 75, pp. 1728-1734, Oct. 1996

[26] R. Weikard, C. Pitra, and C. Kühn, "Amelogenin cross- amplification in the family Bovidae and its application for sex determination," Mol. Reprod. Dev., vol. 73, pp. 1333-1337, Oct. 2006.

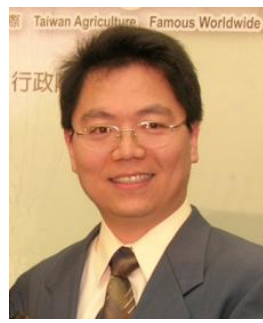

Chuan-Mu Chen was born at Kinman Island, Taiwan, in 1967. He was awarded a Ph.D. degree in animal sciences in 1995 from the National Taiwan University, Taiwan. From 1996 to now, he worked as a Professor at the Department of Life Sciences, National Chung Hsing University. His primary interests focus on molecular embryology, epigenetics, and animal biotechnology. More than 100 papers has been published in SCI journals from his research works and also owned 35 innovation patents in USA, Taiwan, European, and China. 